\title{
THE IMPACT OF SIZE REDUCTION ON THE ENERGY EFFICIENCY, DYNAMICS AND MACHINING PERFORMANCES IN MILLING
}

\author{
P. Haas ${ }^{1 *}$, A. Schorderet ${ }^{2}$, C. Jeannerat ${ }^{3}$, J. Richard ${ }^{1}$, Ch. Balistreri ${ }^{1}$, N. P. Gilani ${ }^{2}$ \\ ${ }^{1}$ University of Applied Sciences and Arts Western Switzerland (HES-SO), inSTI, Geneva, Switzerland \\ ${ }^{2}$ University of Applied Sciences and Arts Western Switzerland (HES-SO), Comatec, Yverdon, Switzerland \\ ${ }^{3}$ University of Applied Sciences and Arts Western Switzerland (HES-SO), CMP, St-Imier, Switzerland \\ ${ }^{*}$ Corresponding author; e-mail: patrick.haas@hesge.ch
}

\begin{abstract}
The Micro 5 -axes milling machine was specifically developed for micro, or mini, technical productions and focused on simplicity and efficiency. It provides functional, qualitative and economical performances. Designed for low cutting forces (HSC technology), it has an excellent dynamics. The first vibration modes and compliances being very high, the machine is insensitive to axes accelerations. It therefore produces excellent surface finishes and high efficiency in finishing. This paper presents the results of an evaluation project. A comparison with a usual size machine is made.
\end{abstract}

\section{Keywords:}

Size reduction; Micro-machine; Milling; Energy; Dynamics; Machining performances; Air consumption; Thermal characteristics; Modal analysis

\section{INTRODUCTION}

The University of Applied Sciences and Arts Western Switzerland (HES-SO) develops a high efficiency 5-axes milling micro-machine Micro ${ }^{5}$. The main idea of the project is to develop a machine for the production of small parts with a high efficiency in terms of energy consumption.

In the bibliography, the existing measures show the energy used to remove the material is about $15 \%$ of the total energy consumed during machining. The idea is to design a machine for the production of small parts with dimensions in relation. The capacity is a cube of $50 \mathrm{~mm}$ length (Fig. 1). The market objectives are the watch and medical industries.

During the project, we found that, many other aspects of this machine are comparable with the best achievable, not only the energy consumption. This paper presents, after 14 months of evaluation tests, the performances of this machine. The measured characteristics are:

- Machining production performances

- Static stiffness

- Dynamic modes, compliances

- Thermal behavior

- Energy consumption: air, electricity

The paper discusses the advantages and disadvantages of the size reduction based on these measurements. At the same time, a usual size machine, a Mikron 5-axes HSM400, has been measured and the results compared to the Micro 5 .
The Micro ${ }^{5}$ has been developed and built completely in the HES-SO academic environment. Today, production rights have been sold to two Swiss machine tool suppliers. Actually, products based on this development are on the market.

A test part has been designed (Fig. 2) and used with several programs in order to evaluate the precision, the surface finish and the achievable production speed. The precision is very good, but the most impressive result in comparison with a standard machine, is the very fine surface finishes we obtained. We discovered that this could be achieved without working on the CNC strategy in regard to the modal frequencies. The analysis of the dynamics of the machine shows that the modal frequencies are very high in comparison with a standard machine. This is a great advantage. Also, the static stiffness is high due to the small length of the axes (therefore small effort loop). These two results lead to the fact a complex CNC strategy is not needed to deal with the generally low modal frequencies of the machine structure. 


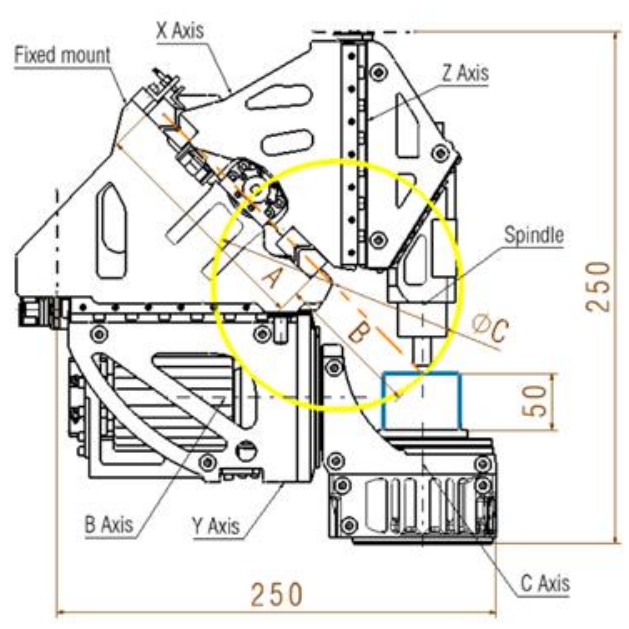

Fig. 1: Micro ${ }^{5}$ conceptual features Yellow circle represents machining effort loop.

\section{FUNCTIONAL PERFORMANCES}

The precision of the axis structure is obtained by a stack of frames precisely machined. There is no adjustment made during the assembly. The frames are assembled by pushing the guides against machined faces. No electronic calibration was performed. Therefore, the precisions displayed could be improved.

The tests have been done without software compensation, thermal control and with only a few drops of oil for the lubrication. 24 dimensional measurements, 27 geometrical one and 2 roughness type $\mathrm{Ra}$ were taken on the test part. The results are summarized in Tab. 1 and 2.

The geometric and dimensional measured accuracies are equal or more precise than the initial geometric accuracy. It confirms the initial hypotheses; the miniaturization positively influences the intrinsic capability of the machine.

\section{STATIC AND DYNAMIC PERFORMANCES}

Since the Micro $^{5}$ machine should provide similar machining capabilities as larger machines for the selected watch and medical industrial applications, mechanical performances are the corner stone of the machine specification sheet.

The static stiffness is the first and most important criterion in the development process. As a result, Micro5's compact architecture and the small effort loop radius (see Fig. 1) inherently minimize the masses of the moving structures and the related inertia simultaneously. Micro ${ }^{5}$ 's very high eigen-frequencies appear as a straightforward result of the approach.

It is well known that the process quality is directly related to the machine stiffness at the Tool-Workpiece interface. The machine dynamic behavior directly affects the milling process stability with the chatter phenomenon [Altintas 1995]. Dynamic stiffness of the machine limits process productivity [Munoa 2006] and surface quality [Zhang 2015].

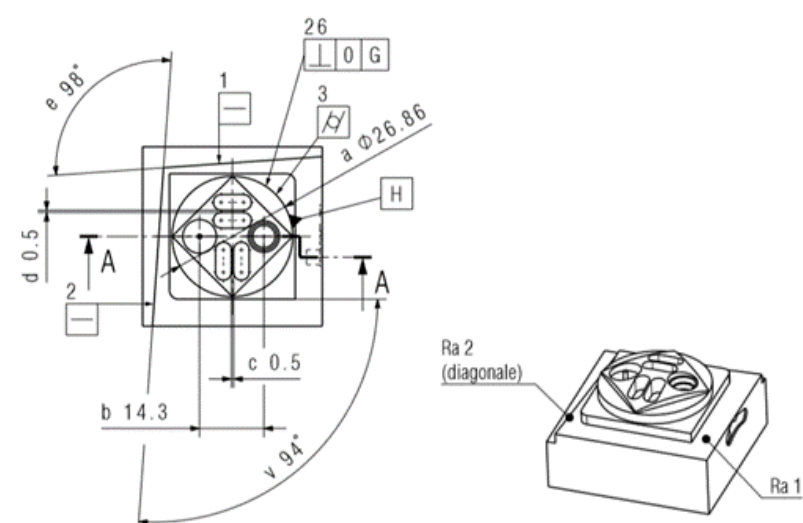

Fig. 2: The test part used to evaluate the machining performances.

Tab. 1: Results in finishing with watch brass.

\begin{tabular}{llll}
\hline Conditions & Names & Units & Values \\
\hline Spindle speed & $\mathrm{n}$ & $\mathrm{rpm}$ & 60 ’000 \\
Number of teeth & $\mathrm{Z}$ & - & 1 \\
Tool diameter & $\mathrm{D}$ & $\mathrm{mm}$ & 3 \\
Feed speed & $\mathrm{Vf}$ & $\mathrm{mm} / \mathrm{min}$ & 600 \\
Cutting speed & $\mathrm{Vc}$ & $\mathrm{m} / \mathrm{min}$ & 565 \\
Axial / radial pass & $\mathrm{Ap} / \mathrm{Ae}$ & $\mathrm{mm}$ & $0.05 / 0.3$ \\
Feed by tooth & $\mathrm{fz}$ & $\mathrm{mm}$ & 0.01 \\
Chip flow & $\mathrm{Q}$ & $\mathrm{mm} / \mathrm{min}$ & 9 \\
\hline
\end{tabular}

In this work, machine static and dynamic performances are characterized by the tool-workpiece relative displacement at the Tool Center Point (TCP) $\delta T C P$. Only the machine-tool is characterized, therefore, the tool-workpiece interface is not considered. During operation, we consider 3 types of excitation forces: process forces, axes dynamic forces (accelerations), environmental forces (ground, devices...).

Tab. 2: Micro5 specifications.

\begin{tabular}{|l|l|l|}
\hline Precision of machine & Units & Values \\
\hline Straightness of axis & $\mu \mathrm{m} /(\mathrm{x}) \mathrm{mm}$ & $<2 / 50$ \\
\hline Orthogonality of axis & $\mu \mathrm{m} /(\mathrm{x}) \mathrm{mm}$ & $<9 / 50$ \\
\hline Beat of rotary axis & $\mu \mathrm{m}$ & 2 \\
\hline Bidirectional repeatability & $\mu \mathrm{m}$ & $\mathbf{0 . 4}$ \\
\hline & & \\
\hline Dimensions and rules & Units & Values \\
\hline Max size workpiece & $\mathrm{mm}$ & 50 \\
\hline Ratio structure/workpiece & - & $\mathbf{5}$ \\
\hline Ratio Loop efforts (ØC) & $\mathrm{kg}$ & 3 \\
\hline Moving mass & $\mathrm{kg}$ & $<\mathbf{1 0}$ \\
\hline Design rule & - & $\mathrm{A} \geq \mathrm{B}$ \\
\hline
\end{tabular}


The static stiffness is described with respect to the process forces, while the dynamic behavior is described with respect to the process and the axes forces. Ground and other devices forces are not considered in this work. For both static and dynamic testing configurations, the machine control-loops are active and the axes positions are set at the center of machining volume.

\subsection{Static stiffness}

The direct stiffness values are evaluated at tool center point (TCP) $k_{j j}=F_{j} / \delta_{T C P j}, \mathrm{j}=\mathrm{x}, \mathrm{y}, \mathrm{z}$. Axes are shown in Fig. 3.

The measurement setup is classical: the force $F_{j}$ is applied using a pneumatic actuator (Festo AEVC 20 5) and measured by means of HBM U9B or U9C load cells. Two inductive sensors ( $\mu$ Epsilon Eddy NCDT) are used to measure the workpiece holder $\delta_{w j}$ and dummy tool displacements $\delta_{t j}$. The relative $\delta_{T C P j}$ is then calculated from $\delta_{w j}$ and $\delta_{t j}$ values introduced in a geometric relationship.

Table 3 shows the stiffness values of the two machines. One observes that, despite the great structural size difference between these machines, the values are quite near. This is mainly due to the smaller effort loop radius of the Micro ${ }^{5}$ machine.
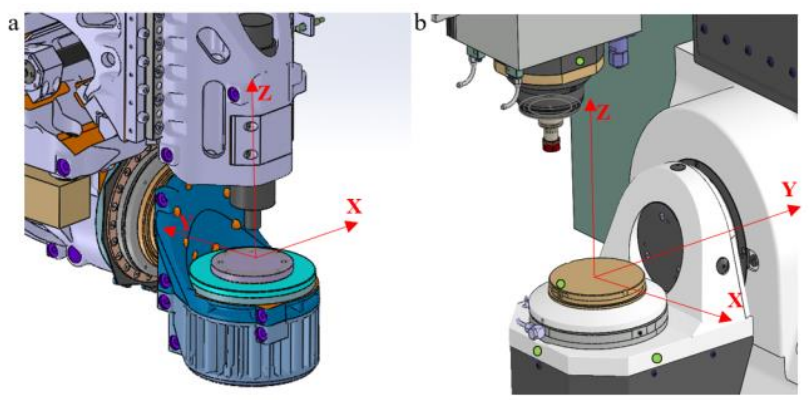

Fig. 3: Reference axes: left: micro5; right: HSM400.

The largest difference appears for the $Z$ axis stiffness, the Micro ${ }^{5}$ being 3 times less stiff than the HSM400. One can notice that this machine is almost 3 times stiffer in $Z$ direction than in $X$ or $Y$. Both machines show the same stiffness along the $Y$ axis.

\subsection{Dynamics: eigen-properties and modal compliances}

The machine dynamics study is based on its modal properties, which were extracted using a standard experimental modal analysis. An impact hammer (Dytran $0.236 \mathrm{mV} / \mathrm{N}$ ) and triaxial accelerometer (Brüel \& Kjaer 4520) were used.

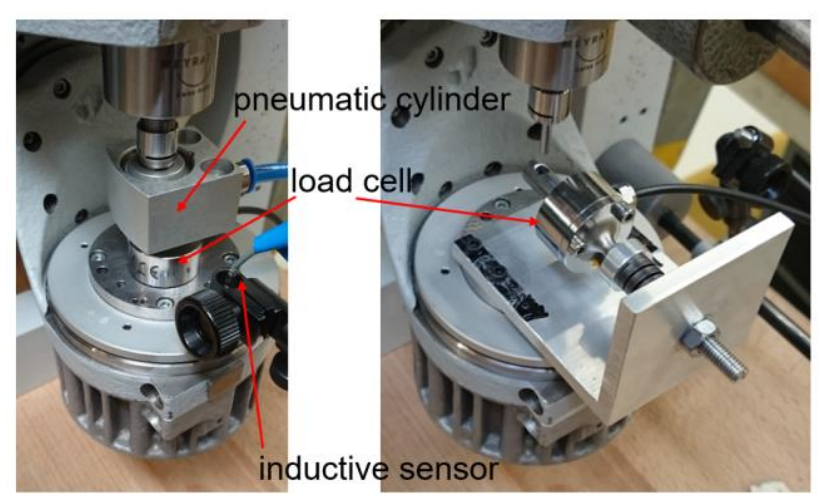

ZZ loading

$X X$ or YY loading

Fig. 4: Micro 5 tool-workpiece loading setup.

Tab. 3: Direct stiffness values for Micro 5 and HSM400 machines.

\begin{tabular}{|c|r|r|r|c|}
\cline { 2 - 4 } \multicolumn{1}{c|}{} & $\mathrm{k}_{\mathrm{TCPx}}$ & $\mathrm{k}_{\mathrm{TCPyy}}$ & $\mathrm{k}_{\mathrm{TCPzz}}$ & \multicolumn{1}{c}{} \\
\hline Micro $^{5}$ & 7.59 & 10.34 & 9.82 & {$[\mathrm{~N} / \mathrm{um}]$} \\
\hline HSM400 & 12.02 & 10.13 & 28.85 & {$[\mathrm{~N} / \mathrm{um}]$} \\
\hline ratio & 0.63 & 1.02 & 0.34 & {$[-]$} \\
\hline
\end{tabular}

The first 4 modes are depicted in Fig. 5. For clarity purpose, FEA results are represented instead of experimental ones.

Mode shape correspondence was used to compare the machines modal behavior, focusing on modes producing tool-workpiece modal displacement at TCP.

In Tab. 4 one observes that the Micro ${ }^{5}$ machine eigenfrequencies are at least 2 times higher than corresponding HSM400 modes. The lowest frequency being 4 times higher $(234 \mathrm{~Hz}$ vs $58 \mathrm{~Hz})$. Micro ${ }^{5}$ modes $\mathrm{A}$ and $\mathrm{C}$ show high damping ratio due to control loop contribution.

The dynamic behavior of a machine submitted to process and/or axes acceleration forces is better described using the modal compliances. $C_{r a k}$ is defined as the structural compliance of mode number $r$ when the structure is subjected to a force applied along DOF (degree of freedom) number $\mathrm{k}$, the displacement being evaluated at DOF number a:

$$
C_{r a k}(\omega)=\frac{1}{\sqrt{\left(1-\frac{\omega^{2}}{\omega_{r}^{2}}\right)^{2}+4 \eta_{r}^{2} \frac{\omega^{2}}{\omega_{r}^{2}}}} \frac{p_{r a} p_{r k}}{\omega_{r}^{2}}
$$

where $\omega$ is the frequency at which the compliance is evaluated, $p_{r i}$ is the i-th component of the r-th eigen-vector, $\omega_{r}$ the $r$-th eigen-frequency and $\eta_{r}$ the $r$-th modal damping coefficient.

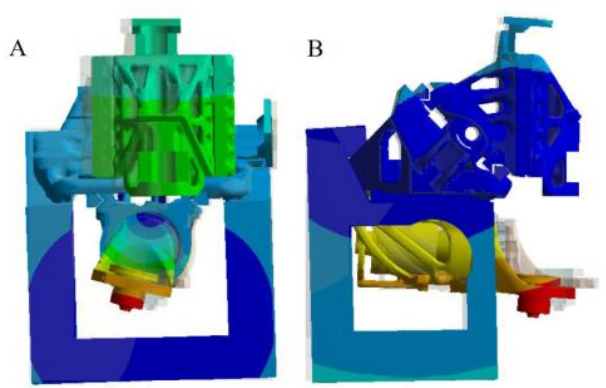



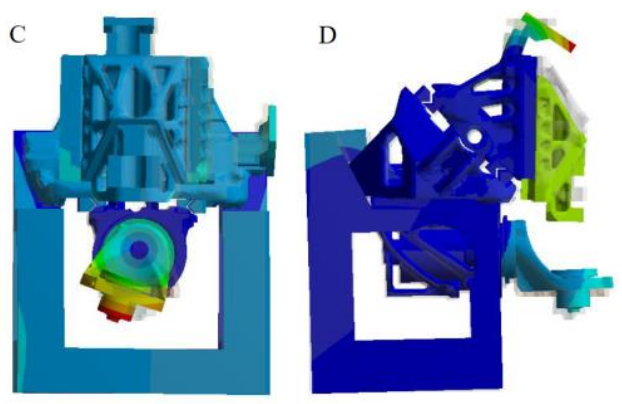

G

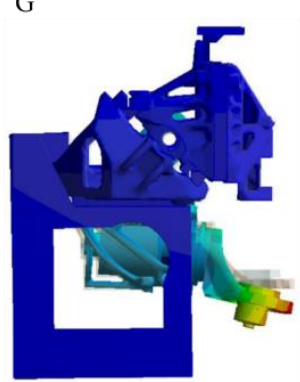

$\mathrm{H}$

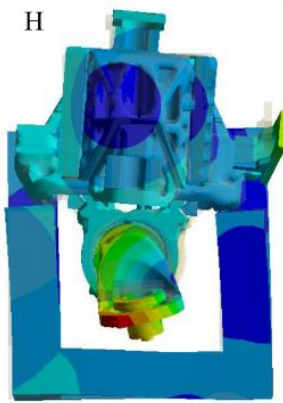

Fig.5: Micro5 mode-shapes $A, B, C, D$ from FEA.

Tab.4: Eigen-frequencies and damping for Micro ${ }^{5}$ and HSM400 machines.

\begin{tabular}{|l|l|l|l|l|l|} 
mode A & mode B & mode C & mode D & mode G & mode H \\
\hline
\end{tabular} eigen-frequency $[\mathrm{Hz}]$

\begin{tabular}{|c|r|r|r|r|r|r|}
\hline Micro $^{5}$ & 234 & 239 & 275 & 306 & 476 & 506 \\
\hline HSM400 & 58 & 106 & 136 & 98 & - & - \\
\hline freq. ratio & 4.03 & 2.25 & 2.02 & 3.12 & - & - \\
\hline \multicolumn{7}{|c|}{ modal damping [-] } \\
\hline Micro $^{5}$ & $13.4 \%$ & $5.8 \%$ & $11.6 \%$ & $1.7 \%$ & $2.9 \%$ & $1.7 \%$ \\
\hline HSM400 & $2.4 \%$ & $1.1 \%$ & $5.4 \%$ & $2.4 \%$ & - & - \\
\hline
\end{tabular}

The dynamic compliances were evaluated considering the points and directions of applied force depicted in Fig. 6 . The dynamic compliances where evaluated for each machinetool considering the relative displacement at TCP, due to a specific force.

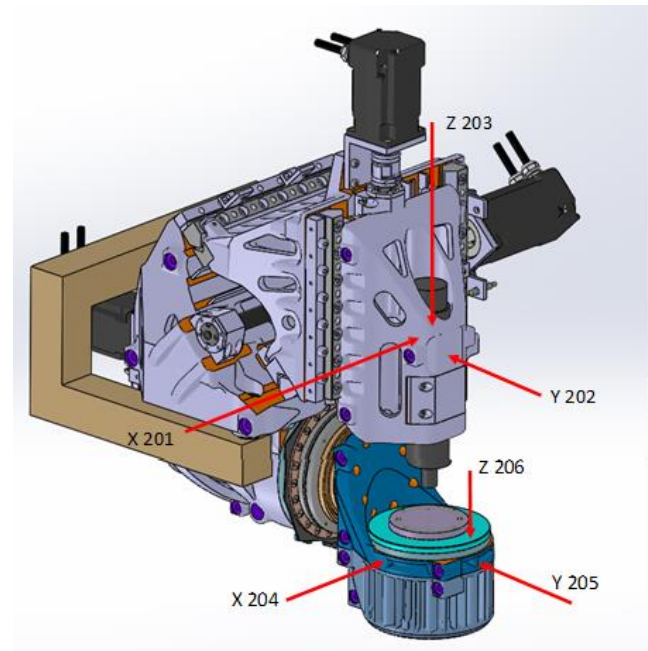

Fig. 6: Locations and directions of impact force for compliance analysis.
As defined by the axes in Fig. 6, the impact forces were applied on the spindle carrier or the workpiece holder depending on the specific force considered.

The obtained results illustrate two interesting points. First the compliance values of the Micro ${ }^{5}$ machine are greater than the HSM400 ones (Fig 7 and Fig.8, e.g. 0.512 um/N vs $0.118 \mathrm{um} / \mathrm{N}$ for mode D $306 \mathrm{~Hz} / 98 \mathrm{~Hz}$ compliance CDzz). Second, and most important (Fig 9) : the Micro ${ }^{5}$ significant modal compliances are above $200 \mathrm{~Hz}$ while HSM400 shows several significant modal compliances from $58 \mathrm{~Hz}$. Fig. 9 illustrates this feature with the $Z$ compliance due to $X$ axis excitations. This compliance influences surface quality in end milling.

The spectral contents of axes accelerations used in standard CNC are far below $200 \mathrm{~Hz}$, mainly because of the sub- $100 \mathrm{~Hz}$ eigen-frequencies of standard machine-tools. In case of vibrations, the acceleration bandwidth is reduced, for example by a jerk limitation approach, or with specific strategies as in [Altintas 2012]. Therefore, the fact that the machine's compliances are above $230 \mathrm{~Hz}$ contributes to the observed Micro ${ }^{5}$ excellent dynamic behavior and machining performances with a standard CNC.

Modal compliances : Micro5

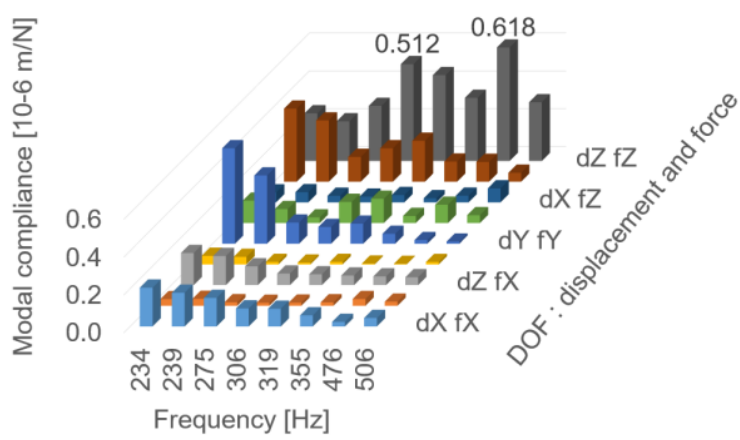

Fig. 7: Micro 5 Tool-Workpiece modal compliances for linear axes forces.

Modal compliances : HSM400

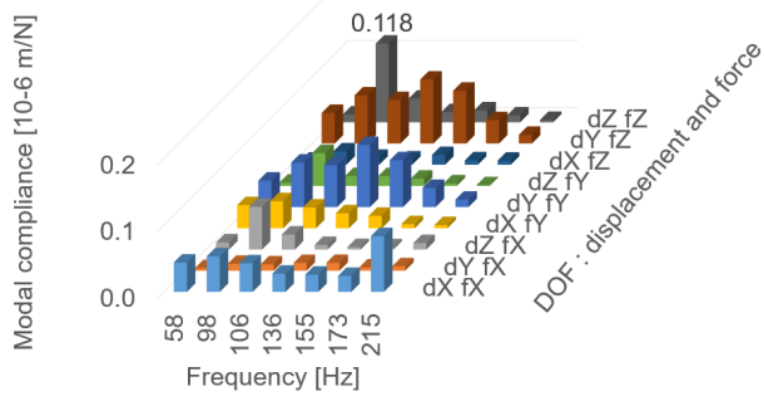

Fig. 8: HSM400 Tool-Workpiece modal compliances for linear axes forces. 


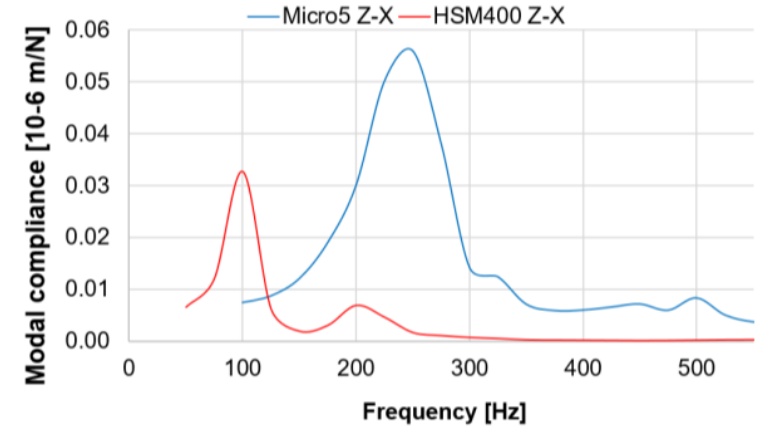

Fig.9: Micro $^{5}$ vs HSM400 Tool-Workpiece compliances for force on linear axis $X$ carrier.

\section{THERMAL ASPECTS AND ENERGY CONSUMPTION}

The thermal deviations have been measured using a laser interferometer and parts in invar specially designed to support the mirrors (Fig. 10). The machine was also instrumented with surface thermocouples located on the frame and on the spindle (Fig. 11). Although, some cycles of heating have been described by a few authors, for example [Gebhardt 2012], simple heating modes have been used. These are stand-by or a spindle running at a given speed.

We found a thermal variation of the axis typically about 6 microns when cold (Fig. 12). After a heating period in standby, this value becomes less than 2 microns (Fig. 13). The Micro $^{5}$ machine with small dimensions, gives small deformations. The measured heating time to reach $95 \%$ of the final temperature value is 6 hours. The time constant (time for $67 \%$ of variation) is about 2 hours. From this point of view, the acceptable time to start a production is quite similar to an usual size drilling machine. In the case of the micro machine, the masses are lower, but the thermal dissipated powers too.

The consumption of each component has been measured according to ISO 14955-2 standard for the Micro ${ }^{5}$ and the standard-sized machine (Tab. $5-7$ ). The measurements have been done during the production of part shown in Fig. 2 and also for some simple typical situations. The energy consumption is really repeatable. A factor of 10 for some configurations has been fund (Tab. 7). In some others, the two consumptions were quite the same or the difference greatly reduced. The important result is the fact the machining strategy should be adapted to size of the machine. On the big machine, big pass depths shall be used in order to reduce the machining time.

The stand-by consumption is very important. That means the standard machine has to work all the time. Instead the small one can be more in this mode without significant impact on the energy consumption. The global energy consumption has been measured with auxiliaries and groups. For the air consumption equivalence, we used ref. 2.

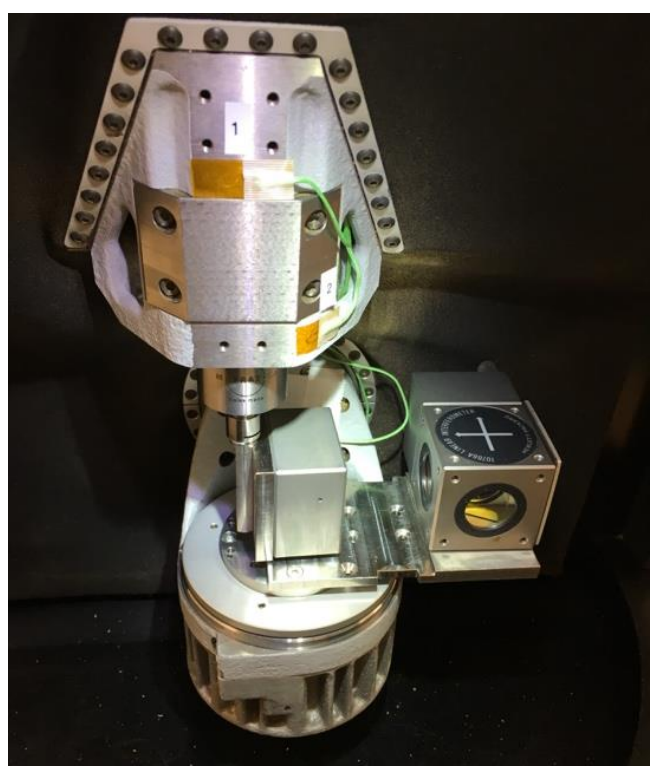

Fig. 10: Mounting of the laser interferometer mirrors.

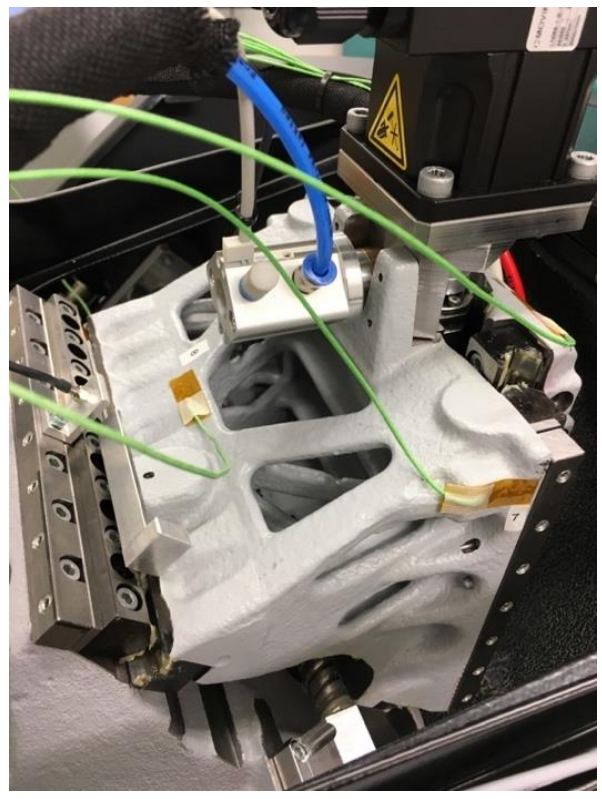

Fig. 11. Surface thermocouple applications.

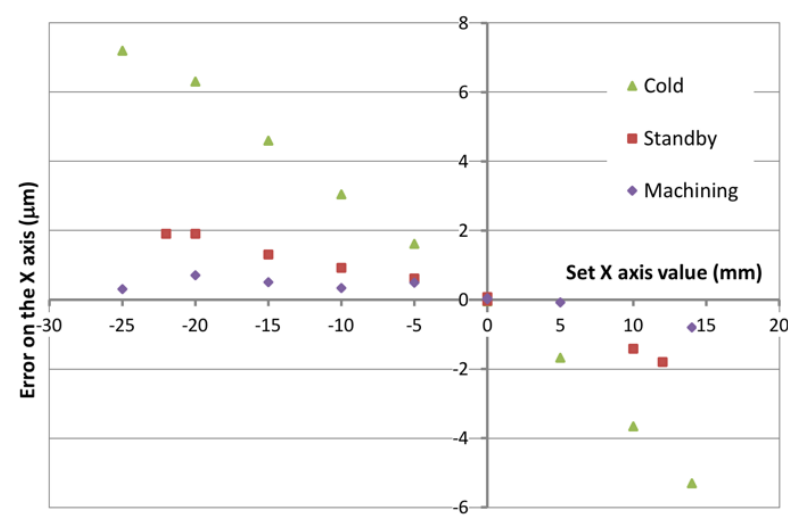

Fig. 12: Error on the $X$ axis position. 


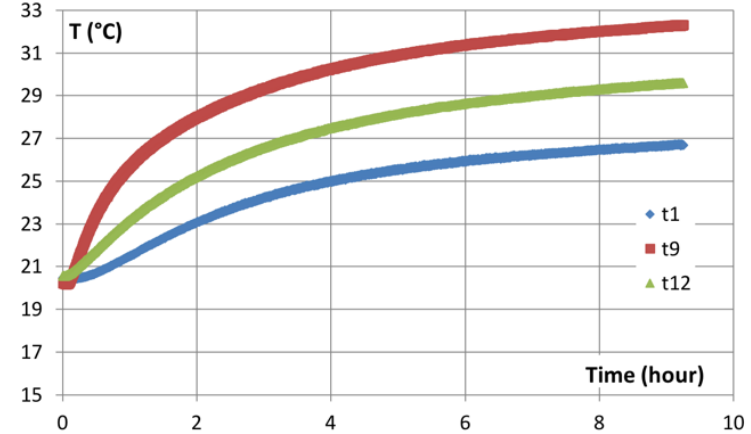

Fig. 13: Typical temperature evolution in standby mode (Micro5).

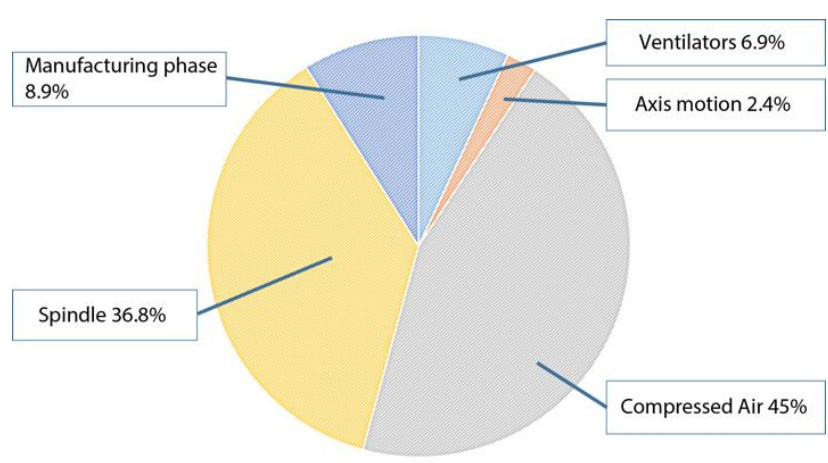

Fig. 14: Micro-machine primary energy balance (without chips).

Tab. 5. Powers in standby mode.

\begin{tabular}{|c|c|c|}
\hline \multicolumn{3}{|c|}{ Power in standby } \\
\hline & Mikron HSM 400 & Micro5 \\
\hline Electricity (W) & 1440 & 210 \\
\hline Compressed air [NL/min] & 300 & 70 \\
\hline Compressed air equivalent [W] & 2160 & 504 \\
\hline Total power [W] & $\mathbf{3 6 0 0}$ & $\mathbf{7 1 4}$ \\
\hline
\end{tabular}

Tab. 6: Powers of accessories and spindle.

\begin{tabular}{|c|c|c|}
\hline \multicolumn{3}{|c|}{ Accessories } \\
\hline Movement / accessory & $\begin{array}{c}\text { Mikron HSM 400 } \\
{[\mathbf{W}]}\end{array}$ & Micro5 [W] \\
\hline X axis $10^{\prime} 000 \mathrm{~mm} / \mathrm{min}$ & 210 & 15 \\
\hline Y axis $10^{\prime} 000 \mathrm{~mm} / \mathrm{min}$ & 150 & 10 \\
\hline Z axis $10^{\prime} 000 \mathrm{~mm} / \mathrm{min}$ & 390 & 10 \\
\hline B axis $20^{\prime} 000 \mathrm{deg} / \mathrm{min}$ & 1200 & 100 \\
\hline C axis $20^{\prime} 000 \mathrm{deg} / \mathrm{min}$ & 120 & 10 \\
\hline Spindle $20^{\prime} 000 \mathrm{rnd} / \mathrm{min}$ & 690 & 20 \\
\hline Spindle $40^{\prime} 000 \mathrm{rnd} / \mathrm{min}$ & 1530 & 30 \\
\hline Cooling system & 1900 & - \\
\hline
\end{tabular}

The conclusions of the energy consumption analysis are the following:

- The standby power is generally very high
- The cooling power and the air supply represent between 40 and $70 \%$ of the total consumption

- To reduce the energy consumption, the spindle shall be use at full cutting capacity with a related program strategy

\section{LIFE CYCLE ANALYSIS - PRIMARY ENERGY BALANCE}

\subsection{Primary energy balance}

We use here the Cumulative Energy Demand (CED) as LCA method. From the inventory resulting fro the lifecycle model, this method counts primary energies: Fossil, Nuclear, Biomass, Hydraulic and Solar associated with wind and geothermal energy. Mainly we consider here the sum of those energies. According to Ecoinvent V2.2 dataset "Milling, steel, small part/RER" $64 \%$ of primary energy is due to the chips material itself, and a large part of the remaining energy is due to auxiliary power (flushing, compressed air, cooling). We have defined the Functional Unit (FU) as the production of $1 \mathrm{~kg}$ of chips out of chromium steel.

With this chosen functional unit FU, 94\% of the primary energy is dedicated to chips on a micro-machine. In all rigor, the functional unit FU does not allow getting the chips out of the system boundary, but to highlight the differences we shall ignore the chips (as this is a common consumption for all scenarios), then it follows Fig. 14.

The contribution of the "Manufacturing phase" infrastructure is small $(<9 \%)$ compared to the consumables. The major contribution comes from the spindle $(<37 \%)$ and the compressed air consumption (45\%). The contribution to accelerate the machine's axis is very small $(1.2 \%)$ so that the axis kinetic energy is negligible. Even with axis much heavier, the kinetic energy is small relative to cutting energy. We deduce that at the micro-machine level (or even a little bigger) the mass is not a key factor of energy consumption

Tab.7: Consumption comparison.

\begin{tabular}{|c|c|c|c|c|c|}
\hline \multirow{2}{*}{$\begin{array}{l}\text { Cycle / Machining } \\
\text { program }\end{array}$} & \multicolumn{2}{|c|}{ Mikron HSM 400} & \multicolumn{2}{|c|}{ Micro5 } & \multirow{2}{*}{$\begin{array}{c}\text { Mikron } \\
\text { HSM 400 / } \\
\text { Micro5 }\end{array}$} \\
\hline & Cycle time & Consump. [Wh] ${ }^{*}$ & Cycle time & $\begin{array}{l}\text { Consump. } \\
{[\mathrm{Wh}]^{*}}\end{array}$ & \\
\hline $\begin{array}{l}\text { Roughing, no } \\
\text { machining Micro5 }\end{array}$ & $12 \min 18 \mathrm{~s}$ & $791+443=1234$ & $7 \min 55 s$ & $37+67=104$ & 11.9 \\
\hline $\begin{array}{l}\text { Roughing, with } \\
\text { machining Micro5 }\end{array}$ & $12 \min 18 \mathrm{~s}$ & $796+443=1239$ & $7 \mathrm{~min} 55 \mathrm{~s}$ & $40+67=107$ & 11.6 \\
\hline $\begin{array}{l}\text { Roughing, no } \\
\text { machining Mikron }\end{array}$ & $1 \min 28 \mathrm{~s}$ & $46+55=101$ & $x$ & $x$ & 1.0 \\
\hline $\begin{array}{l}\text { Roughing, with } \\
\text { machining Mikron }\end{array}$ & $1 \min 28 \mathrm{~s}$ & $75+55=130$ & $\mathrm{x}$ & $\mathrm{x}$ & 1.2 \\
\hline
\end{tabular}

*Consumption : Electricity + Equivalent compressed air $=$ total

\subsection{Ecodesign directive for machine tool}

The practical energy consumption measures of the micromachine have been much lower than those of conventional machines during finishing tasks. In roughing, with a higher spindle power and a tool engagement in material more important, machining is done faster; the energy to the cut is almost identical. This has been shown by machining a same part in 12.5 minutes on a micro-machine and in 1.5 minutes on a standard machine (Tab. 7).

The approach of the machine choice should be as follows. This is primarily to clarify the need for a given application: what kind of part is to be machined, what are the materials, what batch sizes, what dimensional requirements, and so 
on. The answers to these questions then make it possible to define the type of machining and in particular the tools that will be used.

The size of the tools is a key factor; indeed, with the material to be machined, this essentially conditions the required cutting power. This then conditions the choice of the spindle and its power; from this flows the auxiliary powers to be implemented.

Consequently, the comparison has to be made with caution; however, it can be noted that below a certain size, the energy balance due to the axes is negligible. Even ignoring the chips, the gray energy represented by the infrastructure of the machine remains low, and therefore, below a certain size, little dependent on dimensions.

\section{CONCLUSION}

The energy and life cycle analyses lead to the following:

- Strong impact of chips

- Strong impact of auxiliary powers

- Importance of spindle power for machining

- The kinetic energy of axis is of little importance for the energy consumption

- Micro-machines are very efficient in finishing and well dedicated to watch and medical industries

We highlighted important points related to the reduction of the machine size:

- Due to the small effort loop radius, the machine stiffness at TCP are near to a standard size machine

- Modal frequencies and compliances are shifted above $200 \mathrm{~Hz}$ (typically $58 \mathrm{~Hz}$ for the compared standard machine)

- Excellent dynamics and surface finish

- Small thermal expansions due to small dimensions

\section{SUMMARY}

This paper summarizes the results of the project EcoCarac to evaluate the performances in terms of machining capability, dynamics, compliance, thermal stability and energy consumption of a reduced size milling machine.

\section{ACKNOWLEDGMENTS}

The project \# 51352 EcoCarac was funded by the HES-SO thematic Research program EcoSwissMade 2015 on manufacturing.

\section{REFERENCES}

[Altintas 1995] Y. Altintas, E. Budak, Analytical Prediction of Stability Lobes in Milling, CIRP Annals, Vol 44, Issue 1, 1995.

[Altintas 2012] Y. Altintas, M.R. Khoshdarregi, Contour error control of CNC machine tools with vibration avoidance, CIRP Annals, Manufacturing Technology, 61, 2012.

[Behrendt 2012] T. Behrendt, A. Zein, S. Min, Development of an energy consumption monitoring procedure for machine tools, CIRP Annals - Manufacturing Technology, 2012, vol. 61, pp. $43-46$.
[Ecoinvent 2017] V2.2 dataset "Milling, steel, small part /RER".

[Gontarz 2010] A. Gontarz, L. Weiss, K. Wegener, Energy consumption measurement with a multichannel measurement system on a machine tool, IN-TECH 2010, Prague, Czech Republic, 14 - 16 September, 2010.

[Gebhardt 2012] M. Gebhardt, P. von Cube, W. Knapp, K. Wegener, Measurement set-ups and cycles for thermal characterization of axes of rotation of 5-axis machine tools, 12th euspen International Conference, Stockholm, June 2012.

[Iglesias 2018] A. Iglesias, Z. Dombovari, G. Gonzalez, Jokin Munoa, G. Stepan, Optimum Selection of Variable Pitch for Chatter Suppression in Face Milling Operations, Materials 12(1), December 2018.

[ISO 2016] ISO Standard 14955-2

[Jeannerat 2016] The general characteristics of the HESSO Micro ${ }^{5}$, HES-SO EcoSwissMade internal report, 2013.

[Lee 2016] J-Y Lee, Y-J Shin, M-S Kim, E-S Kim, H-S Yoon, S-Y Kim, Y-C Yoon, S-H Ahn, A simplified machine- tool power-consumption measurement procedure and methodology for estimating total energy consumption, Journal of Manufacturing Science and Engineering, May 2016, Vol. 138, 051004-1.

[Munoa 2006] J. Munoa, M. Zatarain, I. Bediana, Determination of the Cutting Performance and Dynamic Behaviour of Universal Milling Machines by means of a Stability Model, ISMA2006-International Conference on Noise and Vibration Engineering, Leuven, Belgium, Sep 2006.

[Zhang 2015] S.J. Zhang, S. To, G.Q. Zhang, Z.W. Zhu, A review of machine-tool vibration and its influence upon surface generation in ultra-precision machining, International Journal of Machine Tools and Manufacture, Volume 91, April, 2015. 